Article

\title{
Botulinum Toxin-Chitosan Nanoparticles Prevent Arrhythmia in Experimental Rat Models
}

\author{
David Sergeevichev *, Vladislav Fomenko ${ }^{\circledR}$, Artem Strelnikov, Anna Dokuchaeva, \\ Maria Vasilieva, Elena Chepeleva, Yanina Rusakova, Sergey Artemenko, Alexander Romanov, \\ Nariman Salakhutdinov and Alexander Chernyavskiy \\ E. Meshalkin National Medical Research Center of the Ministry of Health of the Russian Federation, 15 \\ Rechkunovskaya Str., 630055 Novosibirsk, Russia; vladislav@ngs.ru (V.F.); agstrelnikov@gmail.com (A.S.); \\ a_dokuchaeva@meshalkin.ru (A.D.); vasilievam@yandex.ru (M.V.); e_chepeleva@meshalkin.ru (E.C.); \\ yarojana@mail.ru (Y.R.); s_artemenko@meshalkin.ru (S.A.); abromanov@mail.ru (A.R.); \\ anvar@nioch.nsc.ru (N.S.); amchern@mail.ru (A.C.) \\ * Correspondence: d_sergeevichev@meshalkin.ru
}

Received: 2 June 2020; Accepted: 27 July 2020; Published: 2 August 2020

\begin{abstract}
Several experimental studies have recently demonstrated that temporary autonomic block using botulinum toxin (BoNT/A1) might be a novel option for the treatment of atrial fibrillation. However, the assessment of antiarrhythmic properties of BoNT has so far been limited, relying exclusively on vagal stimulation and rapid atrial pacing models. The present study examined the antiarrhythmic effect of specially formulated BoNT/A1-chitosan nanoparticles (BTN) in calcium chloride-, barium chloride- and electrically induced arrhythmia rat models. BTN enhanced the effect of BoNT/A1. Subepicardial injection of BTN resulted in a significant antiarrhythmic effect in investigated rat models. BTN formulation antagonizes arrhythmia induced by the activation of $\mathrm{Ca}, \mathrm{K}$ and Na channels.
\end{abstract}

Keywords: botulinum toxin A1; chitosan nanoparticles; antiarrhythmics; pharmacological models of arrhythmia; electrically induced arrhythmia

\section{Introduction}

Botulinum toxin (BoNT) is a safe and efficient therapeutic means to treat a variety of conditions characterized by the hyperfunction of nerve terminals [1,2]. Recently, there has been a growing interest in BoNT for the treatment of atrial fibrillation (AF). Initially, Tsuboi et al. [3] demonstrated that BoNT injected into the sinoatrial fat pad inhibited a decrease in sinus rate in response to vagus nerve stimulation and suggested that BoNT can inhibit ganglionic neurotransmission in the dog heart in situ. Later, Oh et al. [4] demonstrated that direct injection of BoNT in epicardial fat pads temporally suppressed AF inducibility in dogs. In the first clinical study of BoNT effects on patients undergoing coronary artery bypass surgery, Pokushalov et al. [5] demonstrated that BoNT injection suppresses postoperative atrial fibrillation. Recently, Lo et al. [6] demonstrated that suppression of the four major atrial ganglionated plexi by BoNT may break the vicious cycle of "AF begets AF" by inhibiting autonomic remodeling, and possibly preventing subsequent progression of AF to more persistent forms. In addition, Nazeri et al. [7] found that after one week following injection of BoNT into the atrial fat pads of sheep, the vulnerability of atrial tissue to AF induction and the vagal influence on the atrial effective refractory period were reduced compared to baseline levels.

However, the assessment of antiarrhythmic properties of BoNT has only been studied using experimental models of vagal stimulation [3,4,7] and rapid atrial pacing [6]. Indeed, although the 
effect of BoNT on atrial arrhythmias has attracted much attention, the effects of BoNT on ventricular arrhythmias remain unknown.

Therapeutic doses of botulinum neurotoxin drugs are safe, and side effects are relatively rare. Adverse effects often depend on the injection site: there are skin rash, muscle weakness, fatigue, flu-like symptoms, a dry mouth and dizziness [8]. However, in the "first-in-human" study of the epicardial fat pad botulinum toxin injection for atrial fibrillation prevention, there was no serious adverse effect during the one-year and three-year follow-up period [5,9].

The BoNT block of neuromuscular transmission occurs after a lapse of time $[7,10,11]$ and the blocking effect is temporary, with recovery of neuromuscular transmission within one to six months in skeletal muscles [12] and within three weeks in the heart [4]. Therefore, new formulations that may accelerate the effect of BoNT and increase its duration time are highly desirable. Recently, we have demonstrated that globular chitosan prolongs the block of neuromuscular transmission after the BoNT intramuscular injection in rats [13]. Chitosan is a linear polymer derived from chitin, the second most abundant aminopolysaccharide after cellulose. It is fully biocompatible, studied in numerous pharmaceutical and medical applications, demonstrating the highest possible safety profile [14]. To overcome the poor solubility of linear chitosan in water, we used an improved globular chitosan, Novochizol. Novochizol synthesis comprises a two-step activation of linear chitosan, an intramolecular reaction that cross-links linear chitosan molecules. After the cross-linking procedure, Novochizol can be impregnated with active pharmaceutical ingredients [15].

Therefore, in the present study, we examined the antiarrhythmic effect of BoNT and its formulation with an enhanced globular chitosan (Botulinum_Novochizol, BTN) using calcium chloride-, barium chloride- and electrically induced arrhythmia rat models.

\section{Results}

Normal ECG waves with a sinus rhythm were observed in all investigated models before intravenous or subepicardial injection of test substances and before injection of arrhythmogens.

\subsection{Calcium Chloride-Induced Arrhythmia}

Intravenous injection of calcium chloride $(150 \mathrm{mg} / \mathrm{kg}$ ) caused severe lethal ventricular fibrillation (VF) after a few seconds p.i (Table 1, Figure 1). Neither BoNT/A1 intravenous or subepicardial injection nor subepicardial injection of chitosan nanoparticles prevented lethal VF. Subepicardial injection of BoNT/A1 lead to a slight, statistically insignificant increase in the onset time of VF $(24.4 \pm 2.1 \mathrm{~s}$ in the BoNT/A1 group vs. $8.2 \pm 1.7 \mathrm{~s}$ in the control group, $p=0.288$ ). Subepicardial BTN injection prevented lethal VF in five rats and led to a significant increase in the onset time of VF $(208.6 \pm 46.6 \mathrm{~s}$ in the BTN group vs. $8.2 \pm 1.7 \mathrm{~s}$ in the control group, $p<0.001$ ). However, verapamil was more effective than BTN and prevented lethal VF in eight animals, with an initial onset time of VF of $300.0 \pm 30.0 \mathrm{~s}$ ( $p=0.0000 \mathrm{vs}$. control, $p=0.002 \mathrm{vs}$. BTC group). Only rats demonstrating VF were included in the statistical analysis of the initial onset time of VF: there were 10 animals in the control, BoNT/A1 (i.v. and subepicardial) and chitosan nanoparticles groups, two animals in the verapamil group and five animals in the BTN group (Figure 1).

Table 1. The effects of test substances on $\mathrm{CaCl}_{2}$-induced arrhythmia incidence in anesthetized rats.

\begin{tabular}{ccccc}
\hline Test Substances & $\begin{array}{c}\text { Sinus } \\
\text { Rhythm }\end{array}$ & $\begin{array}{c}\text { Lethal } \\
\text { VF }\end{array}$ & $\begin{array}{c}\text { PVC *, Bigeminy, } \\
\text { Not VF }\end{array}$ & $\begin{array}{c}\text { The Incidence of VF, } p \text { (vs. Saline } \\
\text { Control, Fisher's Exact Test) }\end{array}$ \\
\hline Saline control & 0 & 10 & 0 & $<0.001$ \\
Verapamil & 8 & 2 & 0 & \\
BoNT/A1, i.v. & 0 & 10 & 0 & \\
BoNT/A1, subepicardially & 0 & 10 & 0 & $<0.05$ \\
globular chitosan, subepicardially & 0 & 10 & 0 & \\
BTN, subepicardially & 3 & 5 & 2 & \\
\hline
\end{tabular}

* PVC-premature ventricular contractions. 


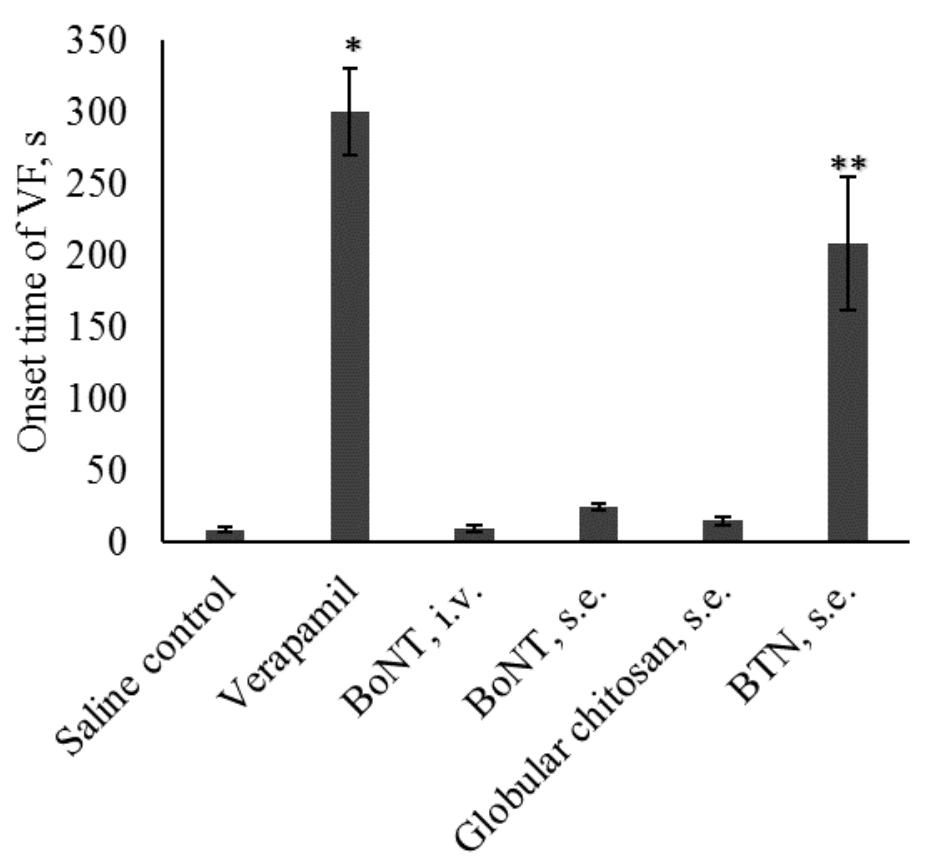

Figure 1. The initial onset time of ventricular fibrillation (VF) after injection of the different tested substances, in the calcium chloride model of arrhythmia. $\mathrm{N}=10$ for saline, BoNT (intravenously and subepicardially) and chitosan nanoparticle groups, $n=2$ for Verapamil group and $n=5$ for BTN group (see Table 1). ${ }^{*} p<0.01$ vs. control, ${ }^{* *} p<0.01$ vs. Verapamil, ANOVA with LSD post hoc test.

Due to all the tested substances, only BTN displayed a significant antiarrhythmic effect $15 \mathrm{~min}$ after subepicardial injection, and only this formulation was chosen for further study.

\subsection{Barium Chloride-Induced Arrhythmia}

Intravenous injection of barium chloride $(7.5 \mathrm{mg} / \mathrm{kg})$ caused premature ventricular contractions (PVC), followed by bigeminy 1-5 min after injection, followed by restoration of sinus rhythm. None of the animals perished.

In comparison with the saline control, subepicardial BTN injection significantly reduced the incidence of ventricular arrhythmias at doses between 0.5 and $5 \mathrm{U}$ (BoNT/A1)/ $\mathrm{kg}$ (Table 2). Unexpectedly, a $0.5 \mathrm{U}(\mathrm{BoNT} / \mathrm{A} 1) / \mathrm{kg}$ dose proved more effective than 1 and $2 \mathrm{U} / \mathrm{kg}$ doses; however, these differences were not significant ( $p=0.63$ and 0.35 , respectively).

Table 2. The effects of test substances on arrhythmia incidence in anesthetized rats, $\mathrm{BaCl} 2$-induced arrhythmia.

\begin{tabular}{cccc}
\hline Test Substances & Sinus Rhythm & $\begin{array}{c}\text { Arrhythmia (PVC, } \\
\text { Bigeminy) }\end{array}$ & $\begin{array}{c}p \text { (vs. Saline Control, Fisher's } \\
\text { Exact Test, Two-Tailed) }\end{array}$ \\
\hline $\begin{array}{c}\text { Saline control } \\
\text { amiodarone }\end{array}$ & 0 & 10 & $<0.001$ \\
BTN, subepicardially & 10 & 0 & $<0.001$ \\
$0.5 \mathrm{U}($ BoNT/A1)/kg & 8 & 2 & $<0.05$ \\
$1 \mathrm{U}(\mathrm{BoNT} / \mathrm{A} 1) / \mathrm{kg}$ & 4 & 6 & $<0.05$ \\
$2 \mathrm{U}(\mathrm{BoNT} / \mathrm{A} 1) / \mathrm{kg}$ & 5 & 5 & $<0.001$ \\
$4 \mathrm{U}(\mathrm{BoNT} / \mathrm{A} 1) / \mathrm{kg}$ & 8 & 2 & $<0.001$ \\
$5 \mathrm{U}(\mathrm{BoNT} / \mathrm{A} 1) / \mathrm{kg}$ & 8 & 2 & \\
\hline
\end{tabular}




\subsection{Electrical Stimulation}

There were no statistically significant differences between the values of $\mathrm{VFT}_{0}$ (threshold of ventricular fibrillation before BTN or lidocaine injection) in different groups. Subepicardial BTN injection increased $\mathrm{VFT}_{1}$ (threshold of ventricular fibrillation after BTN or lidocaine injection) in a dose-dependent manner (Figure 2). VFT (ventricular fibrillation threshold) was increased by $12 \%$ and $10 \%$ upon administration of 1 and $2 \mathrm{U}(\mathrm{BoNT} / \mathrm{A} 1) / \mathrm{kg}$, respectively. These differences were not statistically significant. In contrast, VFT was significantly increased by $18 \%$ and $20 \%$, upon administration of 4 and $5 \mathrm{U}(\mathrm{BoNT} / \mathrm{A} 1) / \mathrm{kg}$, respectively $(p=0.0136$ and 0.0177 , respectively). The reference antiarrhythmic lidocaine increased the VFT by $13 \%(p=0.0344)$.

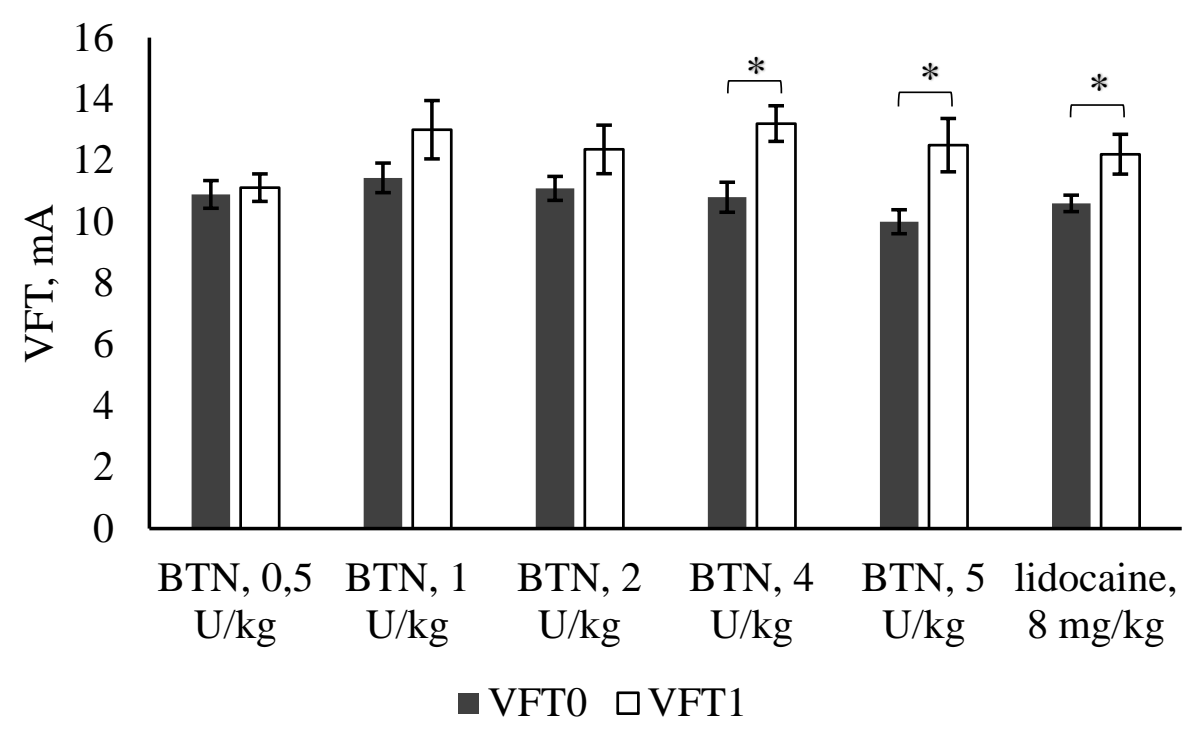

Figure 2. The effect of BTN (subepicardial injection) or lidocaine (i.v.) on VFT in anesthetized rats. $\mathrm{VFT}_{0}$ - minimum electrical intensity that generated VF before injection of BTN or lidocaine; $\mathrm{VFT}_{1}$ - minimum electrical intensity that produced VF after injection of BTN or lidocaine; mean \pm SEM $\left({ }^{*} p<0.05 \mathrm{VFT}_{1}\right.$ vs. $\mathrm{VFT}_{0} ; \mathrm{ANOVA}$ with LSD post hoc test).

\section{Discussion}

Several studies have shown that temporary autonomic block using BoNT might be a novel therapeutic option for the treatment of postoperative AF [4-6,16]. It is well known that BoNT acts on neuromuscular junctions and blocks the exocytotic release of acetylcholine (ACh) stored in synaptic vesicles [17]. ACh is the main neurotransmitter of the parasympathetic nervous system and an internal transmitter of the sympathetic nervous system [18]. The role of the sympathetic and parasympathetic nervous system in the pathophysiology of cardiac arrhythmias is complex [19]. Selective ablation or stimulation of the different components of the autonomic nervous system, such as ganglionic plexi or the vagal nerve, can modulate the activity of this system and treat arrhythmias [20,21]. By blocking $\mathrm{ACh}$ release from the autonomic nerve terminals, BoNT can affect the parasympathetic control of the sinoatrial and atrioventricular node of the heart through the vagal nerve $[3,4,22,23]$.

The antiarrhythmic effects of BoNT injection into ganglionated plexi have been shown to persist for at least one year after cardiac surgery $[5,16]$. However, it is important to find a way to enhance and further prolong this therapeutic effect. Indeed, patients developing new-onset postoperative atrial fibrillation have a high risk of recurrent atrial fibrillation for as long as two years after surgery [24,25]. Recently, we have demonstrated through intramuscular injection in rats [13] that globular chitosan prolongs the effect of BoNT/A1 and decreases its subsequent toxicity. The persistence of this effect on BoNT/A1 will be investigated in a future study. Here, we assessed the influence of globular (nanoprticle) chitosan on the antiarrhythmic properties of BoNT/A1. 
Chitosan is a natural polymer known for its lack of toxicity and immunogenicity, its biodegradability and antimicrobial properties. As such, it is an excellent candidate for a variety of medical and pharmaceutical applications [26,27]. Thanks to their globular form and a high degree of diacylation and in contrast to linear chitosan, globular chitosan used previously [28] and the improved chitosan nanoparticles used in the present study (Novochizol) yield aqueous suspensions equivalent to bona fide solutions. This characteristic is essential for subepicardial or intravenous injection as a clinical application of this compound. As demonstrated in the chloride calcium-induced model of arrhythmia, chitosan nanoparticles alone did not display any antiarrhythmic or arrhythmogenic properties. Thus, the antiarrhythmic effect of BTN is due to the action of BoNT. Accordingly, the dose of BTN was measured as $\mathrm{U}(\mathrm{BoNT}) / \mathrm{kg}$.

No good model of arrhythmia exists that brings together all the essential anatomopathological, electrophysiological, biochemical and molecular factors present in clinical practice [29]. In addition, the assessment of antiarrhythmic properties of BoNT has relied exclusively on experimental models of vagal stimulation $[3,4,7]$ and rapid atrial pacing [6]. In the present work, we used calcium chloride, barium chloride and left ventricle electrical stimulation to devise three different experimental models of arrhythmia in rats. Intravenous infusion of calcium chloride induces ventricular arrhythmias in animals by increasing intracellular free calcium and opening calcium channels [30]. In contrast, barium chloride decreases outward potassium currents [31]. The influence of the drug on $\mathrm{K}$ and Na channels could be assessed in the model of electrical stimulation [32]. Protection against rhythm disturbances caused by these arrhythmogenic factors demonstrates the ability of a compound to act as a potential antiarrhythmic agent.

Intravenous injection is a conventional route of administration for antiarrhythmics used in clinics. Accordingly, we initially administered BoNT/A1 by intravenous injections. However, this mode of administration did not prevent the induced arrhythmias. Instead, antiarrhythmic effects (non-significant for BoNT and statistically significant for BTN) were observed when BoNT/A1 and BTN were injected subepicardially, $15 \mathrm{~min}$ before the injection of calcium chloride. One of the limitations in the chosen rat model is the quasi-impossibility to perform an injection in autonomic ganglia or fat pads or even in the wall of the left atrium. Indeed, although the density of small fibers and ganglia is the highest in the posterior part of the left atrium and around the antrum of the pulmonary veins $[33,34]$, the rat's heart is very small and the heart rate is very high. In addition, a dense network of Ach-containing nerves running over the epi- and endocardial surfaces of left and right ventricles and a widespread distribution of muscarinic $\mathrm{ACh}$ receptors throughout the ventricle have been demonstrated in different species [35-41]. Therefore, we injected the tested substances subepicardially, in the left ventricles.

Since a time-lapse is required for BoNT to block neuromuscular transmission $[7,10,11]$, we injected BoNT/A1 or BTN 15 min before the injection of arrhythmogens. Our results in the calcium chloride model demonstrated that this delay was not sufficient for BoNT/A1 to show significant antiarrhythmic effects. In contrast, BTN demonstrated clear antiarrhythmic effects despite the short time-lapse between the injection of BTN and the injection of the arrhythmogen. At the same time, chitosan nanoparticles alone did not show antiarrhythmic effect. Therefore, we conclude that chitosan nanoparticles accelerate the effect of BoNT/A1. As the next step, we examined the dose-dependency of BTN effects on the incidence of arrhythmias in either a barium chloride model or after electrical myocardial stimulation of the left ventricle.

There were no significant differences between the antiarrhythmic effect at different doses of BTN (0.5-5 U(BoNT)/kg) in the barium chloride model. Instead, all dosages significantly prevented arrhythmias as compared to the control group. On the other hand, there was a clear dose-dependent antiarrhythmic effect of BTN in the electrically induced model of arrhythmia. In addition, in this model, the effects of the 4 and $5 \mathrm{U}(\mathrm{BoNT}) / \mathrm{kg}$ doses were comparable to the effects of lidocaine $(8 \mathrm{mg} / \mathrm{kg})$.

Our results demonstrate that the chitosan nanoparticle formulation of BoNT/A1 prevents arrhythmia induced by an activation of $\mathrm{Ca}, \mathrm{K}$ and $\mathrm{Na}$ channels. The mechanism of this effect 
remains unclear. Further study is needed to understand whether BTN acts on ionic channels directly or whether its effect is mediated by the influence on the autonomic nervous system.

In clinical practice, the use of BoNT or BTN for the treatment of postoperative atrial fibrillation may become a promising alternative to the radiofrequency ablation of ganglionated plexi. Ablation techniques cause permanent destruction of anatomic structures of the heart and may become proarrhythmic $[42,43]$. At the same time, postoperative arrhythmia has been shown to be a transient phenomenon that generally arises in the first week after an operation [44,45]. Accordingly, the temporary nature of the effect of BoNT and subsequent recovery of conduction of the autonomic nervous system constitute an advantage of the investigated technique. Another beneficial finding is that the injection of BoNT into the ganglionated plexi or a subepicardial injection do not cause permanent injury to the autonomic neurons and myocardium.

\section{Materials and Methods}

\subsection{Test Substances}

BoNT/A1 (Xeomin) was purchased from Merz Pharmaceutical Gmbh (Frankfurt am Main, Germany); each vial contained $100 \mathrm{U}$ BoNT/A1.

Chitosan nanoparticles (Novochizol) were provided by Bosti Trading (Nicosia, Cyprus). The average molecular weight of the starting chitosan raw material (Chitoclear by Primex, Siglufjörður, Island) was $450-500 \mathrm{kDa}$, and the degree of deacetylation was at least $90 \%$. While regular, linear chitosan is insoluble at physiological $\mathrm{pH}$, so chitosan nanoparticles may be suspended in aqueous solutions and the resulting suspension may be assimilated to a solution.

BTN was formulated by dissolving the content of one vial (100 U of BoNT/A1) in $1 \mathrm{~mL}$ of a $0.25 \%$ suspension of chitosan nanoparticles in physiological saline. The formulation was used as early as after $24 \mathrm{~h}$, and up to 10 days after preparation.

\subsection{Animals}

Male Wistar rats weighing $410 \pm 40 \mathrm{~g}$ were provided by the vivarium of the Institute of Cytology and Genetics SB RAS (Novosibirsk, Russian Federation). The animals were housed in the vivarium of «E. Meshalkin National medical research center» of the Ministry of Health of the Russian Federation and were allowed free access to water and commercial laboratory complete food. Prior to the experiment, the animals had an acclimatization period of 14 days. A daily physical examination of the animals was performed in accordance with the regulatory requirements. Animals were blindly randomized into groups immediately prior to performing studies.

The use of animals in this study was approved by the Local Ethics Committee of «E. Meshalkin National medical research center» of the Ministry of Health of the Russian Federation. All parts of the protocol were performed in accordance with the recommendations for proper use and care of laboratory animals (European Communities Council Directive 86/609/CEE) and the principles of the Declaration of Helsinki.

\subsection{Anesthesia}

To induce anesthesia, rats were administered a subcutaneous injection of atropine $(0.01 \mathrm{mg} / \mathrm{kg})$ and were subsequently placed in an anesthesia induction chamber with a continuous supply of air containing sevoflurane (3-5\%) (Gas Anesthesia System 21100, Ugo Basile, Gemonio, Italy and Small Animal Ventilator 683, Harvard Apparatus, Holliston, MA, USA). Subsequent to anesthesia, each animal was placed on the operating table, and a $24 \mathrm{G}$ peripheral intravenous catheter was inserted into the tail vein. Anesthesia was maintained using intravenous (i.v.) administration of $20 \mathrm{mg} / \mathrm{kg}$ sodium thiopental solution every 5-10 $\mathrm{min}$. The same catheter was used for intravenous administration of other medications. Mechanical lung ventilation with indoor air was performed using a Rodent Ventilator device (Ugo Basile, Gemonio, Italy) via a tracheostomy tube with a diameter of $3 \mathrm{~mm}$. 


\subsection{ECG Analysis}

Invasive ECG monitoring was performed with peripheral electrode pads. A standard lead II ECG was recorded throughout the experiments using a Schiller AT-6 electrocardiograph (Schiller, Baar, Switzerland). An ECG recording rate of $50 \mathrm{~mm} / \mathrm{s}$ was used.

The ventricular ectopic activity was assessed according to the diagnostic criteria advocated by Lambeth Conventions (II) [46]. The ECGs were analyzed to determine the onset of episodes of arrhythmias, including premature ventricular contraction (PVC), bigeminy, ventricular tachycardia (VT) and ventricular fibrillation (VF). VT was defined as PVCs lasting $\geq 4$ beats. VF was defined as rapid, irregular QRS complexes.

\subsection{Subepicardial Injections}

To perform subepicardial injections, the rats were anesthetized as described above, and subsequently intubated and mechanically ventilated. To access the heart, median sternotomy was performed, with subsequent tissue fixation using fixation devices. The left lung was moved aside to expose the left ventricle, and the tested substances were injected subepicardially using an insulin syringe mounted with a $26 \mathrm{G}$ needle. ECG was monitored throughout the entire procedure. After $20 \mathrm{~min}$ of observation, the rats were euthanized by insufflation of an excessive volume of carbon dioxide for $15 \mathrm{~min}$.

\subsection{Assessment of the Antiarrhythmic Effect}

The antiarrhythmic effect of the tested substances was assessed in three different models of arrhythmia (induction by calcium chloride, barium chloride or left ventricle electrical stimulation). The arrhythmogenic dose of calcium chloride and barium chloride was determined in a preliminary study as the smallest dose that induced heart rhythm disorders in $100 \%$ of the study animals. Clinically approved antiarrhythmics were used as controls for each model of arrhythmia.

\subsection{Calcium Chloride-Induced Arrhythmia}

Wistar rats were randomly divided into the following groups, comprising 10 animas each:

Group 1. Saline control (physiological saline, $0.9 \%$ );

Group 2. Verapamil, intravenously, $2 \mu \mathrm{g} / \mathrm{kg}$;

Group 3. BoNT/A1, intravenously, $5 \mathrm{U} / \mathrm{kg}$;

Group 4. BoNT/A1, subepicardially, $5 \mathrm{U} / \mathrm{kg}$;

Group 5. Chitosan nanoparticles, subepicardially, $0.014 \mathrm{mg} / \mathrm{kg}$;

Group 6. BTN, subepicardially, 5 U(BoNT/A1)/kg.

Arrhythmia was induced by the intravenous injection of $10 \% \mathrm{CaCl}_{2}$ solution (Moschimpharmpreparaty, Moscow, Russian Federation) to reach a final dose of $150 \mathrm{mg} / \mathrm{kg}$. The reference antiarrhythmic verapamil (Ozon, Samara, Russian Federation) was injected intravenously $5 \mathrm{~min}$ before the arrhythmogen. Each control rat received $0.1 \mathrm{~mL}$ saline $5 \mathrm{~min}$ before the injection of the arrhythmogen. Test substances (BoNT/A1, globular chitosan and BTN) were injected intravenously or subepicardially $15 \mathrm{~min}$ before the arrhythmogen.

\subsection{Barium Chloride-Induced Arrhythmia}

The following groups of animals, comprising 10 animas each, were investigated:

Group 1. Saline control (physiological saline, $0.9 \%$ );

Group 2. Amiodarone, $5 \mathrm{mg} / \mathrm{kg}$;

Groups 3 to 7 . Subepicardial injection of BTN $(0.5,1,2,4$ and 5 U(BoNT/A1)/kg). 
Arrhythmia was induced by an intravenous administration of $2 \% \mathrm{BaCl}_{2}$ solution to reach a final dose of $7.5 \mathrm{mg} / \mathrm{kg}$. The $\mathrm{BaCl}_{2}$ stock solution was prepared by dissolving $2 \mathrm{~g}$ of $\mathrm{BaCl}_{2}$ (Sigma-Aldrich, St. Louis, MO, USA) in $100 \mathrm{~mL}$ of physiological saline under aseptic conditions, and when no particulate matter was visible, the solution was sterilized by passing through a $0.1 \mu \mathrm{m}$ syringe filter (Millipore, Burlington, MA, USA).

Amiodarone (Sanofi-Aventis, Paris, France) was used as a reference antiarrhythmic and was injected intravenously $5 \mathrm{~min}$ before $\mathrm{BaCl}_{2}$. Physiological saline was injected into the control rats $5 \mathrm{~min}$ before $\mathrm{BaCl}_{2}$. $\mathrm{BTN}$ was injected subepicardially 15 min before $\mathrm{BaCl}_{2}$.

\subsection{Electrical Stimulation}

Anesthetized rats were subjected to a thoracotomy and left ventricle electrical stimulation using two stainless steel stimulating electrodes. A pacing system analyzer (ERA 300, Biotronik, Lake Oswego, OR, USA) was used to deliver electrical rectangular impulses (pulse-width $5 \mathrm{~m}$, frequency $16.6 \mathrm{~Hz}$ ). Electrical intensity was initially set at $10 \mathrm{~mA}$ and increased in stepwise increments of $1 \mathrm{~mA}$ until VF was observed. This minimum electrical intensity that produced VF was set as the threshold current for induction of VF (VF threshold-VFT).

Six groups of animals were investigated, each group comprising 10 animals. $\mathrm{VFT}_{0}$ was recorded after thoracotomy but before BTN injection. Then, recovery of heart rhythm was observed for $10 \mathrm{~min}$, followed by subepicardial injection of BTN or i.v. injection of lidocaine. $\mathrm{VFT}_{1}$ was recorded $15 \mathrm{~min}$ after injection of $\mathrm{BTN}(0.5,1,2,4$ or $5 \mathrm{U}(\mathrm{BoNT} / \mathrm{A} 1) / \mathrm{kg})$ or lidocaine $(8 \mathrm{mg} / \mathrm{kg})$.

\subsection{Statistical Analysis}

Statistical analyses were carried out using Statistica 13 (TIBCO Software, Palo Alto, CA, USA). Differences were considered significant when $p<0.05$. The incidences of VF or arrhythmias $\left(\mathrm{CaCl}_{2}\right.$ or $\mathrm{BaCl}_{2}$ models, respectively) were compared using two-tailed Fisher's exact test.

The onset times of VF (calcium chloride model) and VFT (electrically induced arrhythmia) were expressed as mean \pm standard error of the mean (SEM). ANOVA with LSD post hoc test was implemented to identify significant differences between groups.

Author Contributions: Conceptualization, D.S. and A.R.; methodology, D.S., V.F., A.S.; software, M.V.; validation, D.S.; formal analysis, M.V.; investigation, A.D., V.F., E.C., Y.R.; resources, Y.R.; data curation, M.V.; writing-original draft preparation, D.S.; writing — review and editing, N.S., S.A.; visualization, D.S.; project administration, A.C. All authors have read and agreed to the published version of the manuscript.

Funding: This research received no external funding.

Conflicts of Interest: The authors declare no conflict of interest.

\section{References}

1. Ramirez-Castaneda, J.; Jankovic, J. Long-term efficacy, safety, and side effect profile of botulinum toxin in dystonia: A 20-year follow-up. Toxicon 2014, 90, 344-348. [CrossRef]

2. Wheeler, A.; Smith, H.S. Botulinum toxins: Mechanisms of action, antinociception and clinical applications. Toxicology 2013, 306, 124-146. [CrossRef] [PubMed]

3. Tsuboi, M.; Furukawa, Y.; Kurogouchi, F.; Nakajima, K.; Hirose, M.; Chiba, S. Botulinum neurotoxin A blocks cholinergic ganglionic neurotransmission in the dog heart. Jpn. J. Pharm. 2002, 89, 249-254. [CrossRef] [PubMed]

4. $\quad$ Oh, S.; Choi, E.K.; Zhang, Y.; Mazgalev, T.N. Botulinum toxin injection in epicardial autonomic ganglia temporarily suppresses vagally mediated atrial fibrillation. Circ. Arrhythmia Electrophysiol. 2011, 4, 560-565. [CrossRef] [PubMed] 
5. Pokushalov, E.; Kozlov, B.; Romanov, A.; Strelnikov, A.; Bayramova, S.; Sergeevichev, D.; Bogachev-Prokophiev, A.; Zheleznev, S.; Shipulin, V.; Lomivorotov, V.V.; et al. Long-term suppression of atrial fibrillation by botulinum toxin injection into epicardial fat pads in patients undergoing cardiac surgery: One-year follow-up of a randomized pilot study. Circ. Arrhythmia Electrophysiol. 2015, 8, 1334-1341. [CrossRef] [PubMed]

6. Lo, L.W.; Scherlag, B.J.; Chang, H.Y.; Lin, Y.J.; Chen, S.A.; Po, S.S. Temporary suppression of cardiac ganglionated plexi leads to long-term suppression of atrial fibrillation: Evidence of early autonomic intervention to break the vicious cycle of "AF begets AF". J. Am. Heart Assoc. 2016, 5, e003309. [CrossRef]

7. Nazeri, A.; Ganapathy, A.V.; Massumi, A.; Massumi, M.; Tuzun, E.; Stainback, R.; Segura, A.M.; Elayda, M.A.; Razavi, M. Effect of botulinum toxin on inducibility and maintenance of atrial fibrillation in ovine myocardial tissue. Pacing Clin. Electrophysiol. 2017, 40, 693-702. [CrossRef]

8. Bakheit, A.M. The possible adverse effects of intramuscular botulinum toxin injections and their management. Curr. Drug Saf. 2006, 1, 271-279. [CrossRef]

9. Romanov, A.; Pokushalov, E.; Ponomarev, D.; Bayramova, S.; Shabanov, V.; Losik, D.; Stenin, I.; Elesin, D.; Mikheenko, I.; Strelnikov, A.; et al. Long-term suppression of atrial fibrillation by botulinum toxin injection into epicardial fat pads in patients undergoing cardiac surgery: Three-year follow-up of a randomized study. Heart Rhythm 2019, 16, 172-177. [CrossRef]

10. Kumar, R.; Kukreja, R.V. The Botulinum Toxin as a Therapeutic Agent: Molecular Structure and Mechanism of Action in Motor and Sensory Systems. Semin. Neurol. 2016, 36, 10-19. [CrossRef]

11. Lebeda, F.J.; Cer, R.Z.; Stephens, R.M.; Mudunuri, U. Temporal characteristics of botulinum neurotoxin therapy. Expert Rev. Neurother. 2010, 10, 93-103. [CrossRef] [PubMed]

12. Rossetto, O.; Seveso, M.; Caccin, P.; Schiavo, G.; Montecucco, C. Tetanus and botulinum neurotoxins: Turning bad guys into good by research. Toxicon 2001, 39, 27-41. [CrossRef]

13. Sergeevichev, D.S.; Krasilnikova, A.A.; Strelnikov, A.G.; Fomenko, V.V.; Salakhutdinov, N.F.; Romanov, A.B.; Karaskov, A.M.; Pokushalov, E.A.; Steinberg, J.S. Globular chitosan prolongs the effective duration time and decreases the acute toxicity of botulinum neurotoxin after intramuscular injection in rats. Toxicon 2018, 143, 90-95. [CrossRef] [PubMed]

14. Khan, M.I.H.; An, X.; Dai, L.; Li, H.; Khan, A.; Ni, Y. Chitosan-based Polymer Matrix for Pharmaceutical Excipients and Drug Delivery. Curr. Med. Chem. 2019, 26, 2502-2513. [CrossRef]

15. Novochizol First-In-Class Polysaccharide Nanotechnology Home Page. Available online: https://www. novochizol.ch/what/ (accessed on 21 July 2020).

16. Pokushalov, E.; Kozlov, B.; Romanov, A.; Strelnikov, A.; Bayramova, S.; Sergeevichev, D.; Bogachev-Prokophiev, A.; Zheleznev, S.; Shipulin, V.; Lomivorotov, V.V.; et al. Botulinum toxin injection in epicardial fat pads can prevent recurrences of atrial fibrillation after cardiac surgery: Results of a randomized pilot study. J. Am. Coll. Cardiol. 2014, 64, 628-629. [CrossRef]

17. Schiavo, G.; Montecucco, C. Clostridial Neurotoxins. In Bacterial Toxins: Tools in Cell Biology and Pharmacology; Aktories, K., Ed.; John Wiley \& Sons: Hoboken, NJ, USA, 2008; pp. 169-192.

18. Roy, A.; Guatimosim, S.; Prado, V.F.; Gros, R.; Prado, M.A.M. Cholinergic activity as a new target in diseases of the heart. Mol. Med. 2015, 20,527-537. [CrossRef]

19. Krul, S.P.J.; Berger, W.R.; Veldkamp, M.W.; Driessen, A.H.G.; Wilde, A.A.M.; Deneke, T.; de Bakker, J.M.T.; Coronel, R.; de Groot, J.R. Treatment of Atrial and Ventricular Arrhythmias through Autonomic Modulation. JACC Clin. Electrophysiol. 2015, 1, 496-508. [CrossRef]

20. Katritsis, D.G.; Pokushalov, E.; Romanov, A.; Giazitzoglou, E.; Siontis, G.C.M.; Po, S.S.; Camm, A.J.; Ioannidis, J.P.A. Autonomic denervation added to pulmonary vein isolation for paroxysmal atrial fibrillation: A randomized clinical trial. J. Am. Coll. Cardiol. 2013, 62, 2318-2325. [CrossRef]

21. Parwani, P.; Abbas, M.; Filiberti, A.; Fleming, C.; Hu, Y.; Garabelli, P.; Mcunu, A.; Peyton, M.; Po, S.S. Low-level vagus nerve stimulation suppresses post-operative atrial fibrillation and inflammation: A randomized study. JACC Clin. Electrophysiol. 2017, 3, 929-938. [CrossRef]

22. Dickson, E.C.; Shevky, R. Botulism. Studies on the manner in which the toxin of clostridium botulinum acts upon the body: The effect upon the autonomic nervous system. J. Exp. Med. 1923, 37, 711-731. [CrossRef]

23. Mehnert, U.; de Kort, L.M.; Wöllner, J.; Kozomara, M.; van Koeveringe, G.A.; Kessler, T.M. Effects of onabotulinumtoxinA on cardiac function following intradetrusor injections. Exp. Neurol. 2016, 285, 167-172. [CrossRef] [PubMed] 
24. Lomivorotov, V.V.; Efremov, S.M.; Pokushalov, E.A.; Karaskov, A.M. New-onset atrial fibrillation after cardiac surgery: Pathophysiology, prophylaxis, and treatment. J. Cardiothorac. Vasc. Anesth. 2016, 30, 200-216. [CrossRef] [PubMed]

25. Lomivorotov, V.V.; Efremov, S.M.; Pokushalov, E.A.; Romanov, A.B.; Ponomarev, D.N.; Cherniavsky, A.M.; Shilova, A.N.; Karaskov, A.M.; Lomivorotov, V.N. Randomized trial of fish oil infusion to prevent atrial fibrillation after cardiac surgery: Data from an implantable continuous cardiac monitor. J. Cardiothorac. Vasc. Anesth. 2014, 28, 1278-1284. [CrossRef] [PubMed]

26. Cheung, R.C.F.; Ng, T.B.; Wong, J.H.; Chan, W.Y. Chitosan: An update on potential biomedical and pharmaceutical applications. Mar. Drugs 2015, 13, 5156-5186. [CrossRef]

27. Kato, Y.; Onishi, H.; Machida, Y. Application of chitin and chitosan derivatives in the pharmaceutical field. Curr. Pharm. Biotechnol. 2003, 4, 303-309. [CrossRef]

28. Krasilnikova, A.A.; Sergeevichev, D.S.; Fomenko, V.V.; Korobeynikov, A.A.; Vasilyeva, M.B.; Yunoshev, A.S.; Karaskov, A.M.; Pokushalov, E.A. Globular chitosan treatment of bovine jugular veins: Evidence of anticalcification efficacy in the subcutaneous rat model. Cardiovasc. Pathol. 2018, 32, 1-7. [CrossRef]

29. Chorro, F.J.; Such-Belenguer, L.; López-Merino, V. Animal models of cardiovascular disease. Rev. Esp. Cardiol. 2009, 62, 69-84. [CrossRef]

30. Barzu, T.; Dam, D.T.; Cuparencu, B.; Komendat, M.; Szasz, E. An analysis of calcium chloride-induced arrhythmias in rats. Agressologie 1978, 19, 293-298.

31. Czopek, A.; Byrtus, H.; Zagorska, A.; Siwek, A.; Kazek, G.; Bednarski, M.; Sapa, J.; Pawlowski, M. Design, synthesis, anticonvulsant, and antiarrhythmic properties of novel N-Mannich base and amide derivatives of b-tetralinohydantoin. Pharm. Rep. 2016, 68, 886-893. [CrossRef]

32. Pugsley, M.K.; Hayes, E.S.; Wang, W.Q.; Walker, M.J.A. Ventricular arrhythmia incidence in the rat is reduced by naloxone. Pharm. Res. 2015, 97, 64-69. [CrossRef]

33. Chevalier, P.; Tabib, A.; Meyronnet, D.; Chalabreysse, L.; Restier, L.; Ludman, V.; Alies, A.; Adeleine, P.; Thivolet, F.; Burri, H.; et al. Quantitative study of nerves of the human left atrium. Heart Rhythm 2005, 2, 518-522. [CrossRef] [PubMed]

34. Tan, A.Y.; Li, H.; Wachsmann-Hogiu, S.; Chen, L.S.; Chen, P.S.; Fishbein, M.C. Autonomic innervation and segmental muscular disconnections at the human pulmonary vein-atrial junction. Implications for catheter ablation of atrial-pulmonary vein junction. J. Am. Coll. Cardiol. 2006, 48, 132-143. [CrossRef] [PubMed]

35. Batulevicius, D.; Pauziene, N.; Pauza, D.H. Architecture and age-related analysis of the neuronal number of the guinea pig intrinsic cardiac nerve plexus. Ann. Anat. Anat. Anz. 2005, 187, 225-243. [CrossRef] [PubMed]

36. Kawano, H.; Okada, R.; Yano, K. Histological study on the distribution of autonomic nerves in the human heart. Heart Vessel. 2003, 18, 32-39. [CrossRef] [PubMed]

37. Pauza, D.H.; Skripka, V.; Pauziene, N.; Stropus, R. Morphology, distribution, and variability of the epicardiac neural ganglionated subplexuses in the human heart. Anat. Rec. 2000, 259, 353-382. [CrossRef]

38. Rysevaite, K.; Saburkina, I.; Pauziene, N.; Noujaim, S.F.; Jalife, J.; Pauza, D.H. Morphologic pattern of the intrinsic ganglionated nerve plexus in mouse heart. Heart Rhythm 2011, 8, 448-454. [CrossRef]

39. Rysevaite, K.; Saburkina, I.; Pauziene, N.; Vaitkevicius, R.; Noujaim, S.F.; Jalife, J.; Pauza, D.H. Immunohistochemical characterization of the intrinsic cardiac neural plexus in whole-mount mouse heart preparations. Heart Rhythm 2011, 8, 731-738. [CrossRef]

40. Saburkina, I.; Rysevaite, K.; Pauziene, N.; Mischke, K.; Schauerte, P.; Jalife, J.; Pauza, D.H. Epicardial neural ganglionated plexus of ovine heart: Anatomic basis for experimental cardiac electrophysiology and nerve protective cardiac surgery. Heart Rhythm 2010, 7, 942-950. [CrossRef]

41. Ulphani, J.S.; Cain, J.H.; Inderyas, F.; Gordon, D.; Gikas, P.V.; Shade, G.; Mayor, D.; Arora, R.; Kadish, A.H.; Goldberger, J.J. Quantitative analysis of parasympathetic innervation of the porcine heart. Heart Rhythm 2010, 7, 1113-1119. [CrossRef]

42. Buckley, U.; Rajendran, P.S.; Shivkumar, K. Ganglionated plexus ablation for atrial fibrillation: Just because we can, does that mean we should? Heart Rhythm 2017, 14, 133-134. [CrossRef]

43. Lo, L.W.; Scherlag, B.J.; Chang, H.Y.; Lin, Y.J.; Chen, S.A.; Po, S.S. Paradoxical long-term proarrhythmic effects after ablating the head station ganglionated plexi of the vagal innervation to the heart. Heart Rhythm 2013, 10, 751-757. [CrossRef] [PubMed] 
44. Aranki, S.F.; Shaw, D.P.; Adams, D.H.; Rizzo, R.J.; Couper, G.S.; VanderVliet, M.; Collins, J.J.; Cohn, L.H.; Burstin, H.R. Predictors of atrial fibrillation after coronary artery surgery: Current trends and impact on hospital resources. Circulation 1996, 94, 390-397. [CrossRef] [PubMed]

45. Rostagno, C.; Blanzola, C.; Pinelli, F.; Rossi, A.; Carone, E.; Stefano, P.L. Atrial fibrillation after isolated coronary surgery. Incidence, long term effects and relation with operative technique. Heart Lung Vessel. 2014, 6, 171-179. [PubMed]

46. Curtis, M.J.; Hancox, J.C.; Farkas, A.; Wainwright, C.L.; Stables, C.L.; Saint, D.A.; Clements-Jewery, H.; Lambiase, P.D.; Billman, G.E.; Janse, M.J.; et al. The Lambeth conventions (II): Guidelines for the study of animal and human ventricular and supraventricular arrhythmias. Pharm. Ther. 2013, 139, 213-248. [CrossRef] [PubMed]

(C) 2020 by the authors. Licensee MDPI, Basel, Switzerland. This article is an open access article distributed under the terms and conditions of the Creative Commons Attribution (CC BY) license (http://creativecommons.org/licenses/by/4.0/). 